\title{
Alleviating the Corrosion of Steel Reinforcement due to Electrochemical Chloride Extraction by Special Electrode Configuration
}

\author{
Wei Feng, Jinxia Xu* , Linhua Jiang, Yingbin Song, Yalong Cao, Qiping Tan \\ College of Mechanics and Materials, Hohai University, Nanjing 210098, PR China \\ *E-mail: xujinxia@hhu.edu.cn
}

doi: $10.20964 / 2017.09 .27$

Received: 2 May 2017 / Accepted: 30 June 2017 / Published: 13 August 2017

\begin{abstract}
This paper aims to alleviate the corrosion of steel in the mortar due to the electrochemical chloride extraction (ECE) through a special electrode configuration. In the ECE treatment with the special electrode configuration, two auxiliary electrodes embedded in the anodic and cathodic electrolytes were serviced as the anode and cathode, respectively. Besides, the steel in the mortar was grounded to reduce the cathodic polarization and the stray current corrosion. By a comparative experiment, the effectiveness of the ECE treatment with the special electrode configuration is evaluated by the chloride profile, potential evolution, half-cell potential, corrosion current density $\left(\mathrm{I}_{\text {corr }}\right)$ (decided by electrochemical impedance spectroscopy (EIS)) and visual examination of steel. The results indicate that the ECE treatments with the traditional and special electrode configurations have similar efficiencies of chloride removal. Compared to the ECE treatment with the traditional electrode configuration, the ECE treatment with the special configuration has a higher initial half-cell potential value and lower initial $\mathrm{I}_{\text {corr }}$ value of steel when the power supply is disconnected. Besides, the half-cell potential value of steel is more rapidly increased and the value of $I_{\text {corr }}$ is more rapidly decreased to a stable value, indicating that a quicker repassivation of steel is obtained by using this special electrode configuration. Accordingly, the corrosion risk of steel due to the ECE treatment has been remarkably alleviated. The reason should be mainly attributed to the decrease of steel polarization during the ECE treatment with the special configuration.
\end{abstract}

Keywords: electrochemical chloride extraction; electrode configuration; electrochemical measurements; corrosion.

\section{FULL TEXT}


(C) 2017 The Authors. Published by ESG (www.electrochemsci.org). This article is an open access article distributed under the terms and conditions of the Creative Commons Attribution license (http://creativecommons.org/licenses/by/4.0/). 